\title{
Olivetti Elea 9003: Between Scientific Research and Computer Business
}

\author{
Giuditta Parolini \\ Innovations in the Communication of Science (ICS-SISSA), \\ giudittaparolini@gmail.com
}

\begin{abstract}
About fifty years ago, Elea 9003, the first Italian mainframe fully transistorized, was built in the Olivetti Electronic Research Laboratory. The mainframe was realized with a drain of international expertise and training on-thejob of scientific staff. The head of the Laboratory, Mario Tchou, had a valuable experience in electronics in the U.S. and his collaborators, at first mainly Italian, were chosen for previous experience in pulse modulation methods. Elea 9003 was built with germanium diodes and transistors. They successfully sold the mainframe on the national market, but Olivetti electronic enterprise did not last. After the unexpected deaths of Adriano Olivetti (1960) and Mario Tchou (1961) there were inner contrasts in the management. Moreover, the national market was very limited and the Italian government did not help in any way the company. Therefore, in 1964 due to financial problems and shortsighted business strategies, Olivetti dismissed its main electronic assets and sold the Electronic Department to General Electric. However, the seeds of the work done by Olivetti Laboratory sprouted later on in computer science thanks to Programma 101, the first desktop computer.
\end{abstract}

Keywords: Second generation mainframe, Research \& development (R\&D), Technology transfer, Olivetti

\section{Olivetti Electronic Research Laboratory}

\subsection{The Birth of Italian Computer Science}

In 1959, the Italian company Olivetti, worldwide known for mechanical typewriters and calculators, officially announced a business mainframe, called Elea 9003, fully transistorized. The first computer designed and manufactured in 
Italy was the outcome of the industrial research done since 1955 by Olivetti Electronic Research Laboratory.

The jump into business computer manufacturing was quite abrupt for Olivetti, but not unsuccessful in the Italian market were Olivetti computers competed with IBM mainframes. During the early 1960s, the Italian company manufactured about a quarter of the large and middle mainframes operating in the country. Olivetti built forty Elea 9003 in only four years and rented them out to important Italian companies - the first customer was in 1960 the textile industry Marzotto and institutions (such as the Energy Corporation ENI and the Italian Insurance Agency Inps).

However, in 1964 due to financial problems and shortsighted business strategies, Olivetti dismissed the main electronic activities. The Italian expertise was taken over by General Electric, which purchased Olivetti Electronic Department.

However, Elea 9003 is a remarkable result because Italian computer science was at its very beginning. Besides Olivetti industrial research, there were only three more projects started in 1954.

Pisa University, in partnership again with Olivetti, began to develop a scientific calculator called CEP (Calcolatrice Elettronica Pisana) and two mainframes built abroad were installed in the country, a computer by National Cash Register at Milan Polytechnic and a Ferranti Mark I at INAC (Italian Institute for Applicative Calculations) in Rome. Both these computers belonged to first generation. In addition, CEP, officially presented in 1961, was only partially transistorized.

\subsection{Olivetti Scientific Enterprise}

The interest of Olivetti for research in computer science began in the early Fifties. Electronic systems were increasing more and more their power in US and Great Britain and Adriano Olivetti, the head of the Italian company, forecast an electronic development for mechanical products.

Olivetti should be prepared for this new business challenge, so, in 1952 the company founded a laboratory in New Canaan, Connecticut, in order to drain knowledge from the US expertise in the field. However, the aim of Olivetti was to create a laboratory in Italy. In 1955, the Olivetti Electronic Research Laboratory was founded in Pisa and hosted for a few months in the Physics Department of the University; the official headquarter instead was in Barbaricina, near Pisa, in a nineteenth century villa.

Olivetti chose Mario Tchou, the son of a Chinese diplomat in Italy, for leading the laboratory. Despite his young age - he was born in 1924 in Rome - he had a 
valuable experience in electronics. In 1945 Tchou moved from Italy to the US where he took a B.E.E. at the Catholic University of America in 1947 and a M.S. at the Polytechnic Institute of Brooklyn in 1949.

Since 1952 Tchou was working as Associate in Electrical Engineering at Columbia University. In those years the Department was chaired by Prof. John R. Ragazzini, whose team gave valuable contributions to classical theory of sampleddata control systems. Tchou himself added between his professional skills to be expert of «digital control system including electronic and electro-mechanical computers». (Rao 2003)

\subsection{Tchou, Mario- Appointment Card at Columbia University ${ }^{1}$}

B.E.E., Catholic University of America, 1947; M.S. Polytechnic Institute of Brooklyn, 1949

1952 (9/10) Appointment - Associate in Electrical Engineering 1952-53

1953 (5/4) School of General Studies 1953-54 - Engineering

1953 (6/24) Reappointment - Associate in Electrical Engineering 1953-54

1954 (6/11) Reappointment - Associate in Electrical Engineering 1954-55

1954 (5/3) School of General Studies 1954-55 - Engineering

1954 (10/5) Leave of Absence 10/15/54 - 6/30/55 without salary

1955 (5/2) School of General Studies 1955-56

\subsection{International Experience for Olivetti Laboratory}

Mario Tchou and Adriano Olivetti met for the first time in New York in 1954, while Mario Tchou was working at Columbia University. Adriano Olivetti was strongly impressed by Tchou who was very well educated and communicative. The young engineer had both scientific competence and managerial attitudes, which suited well with Olivetti's philosophy of a 'responsible' industry².

Thanks to his attitudes, Mario Tchou could promote electronic research between the company management, who did not support the new technology apart from the president Adriano, his son Roberto, and a few other people.

In September 1954 Mario Tchou required a Leave of Absence without pay from Columbia for the period October 15, 1954 to June 30, 1955 and he came back to Italy in December 1954 (Figure1 and Figure2 in Appendix A and B are the original documents from the Columbia Archives).

\footnotetext{
${ }^{1}$ By courtesy of Columbia University Archives.

2 «Seriously interested in people, in social experiments, in the relationship among management, executive and workers», The Asia Magazine (22 October 1961).
} 
The Olivetti Laboratory should be a national value, so Tchou's collaborators (some of them are shown in Figure 3) were mainly Italians at first and they were chosen for previous experience in pulse modulation methods. Only Giorgio Sacerdoti knew already mainframes because he had taken part in the set up of Ferranti Mark computer at Inac.

In the beginning, the only stranger was Martin Friedmann, a Canadian engineer who had developed the magnetic memories for the Ferranti Mark in Manchester. A drain of national and international experiences was necessary to set up the industrial laboratory and develop the ambitious project of a computer made in Italy (Filippazzi and Sacerdoti 1992).

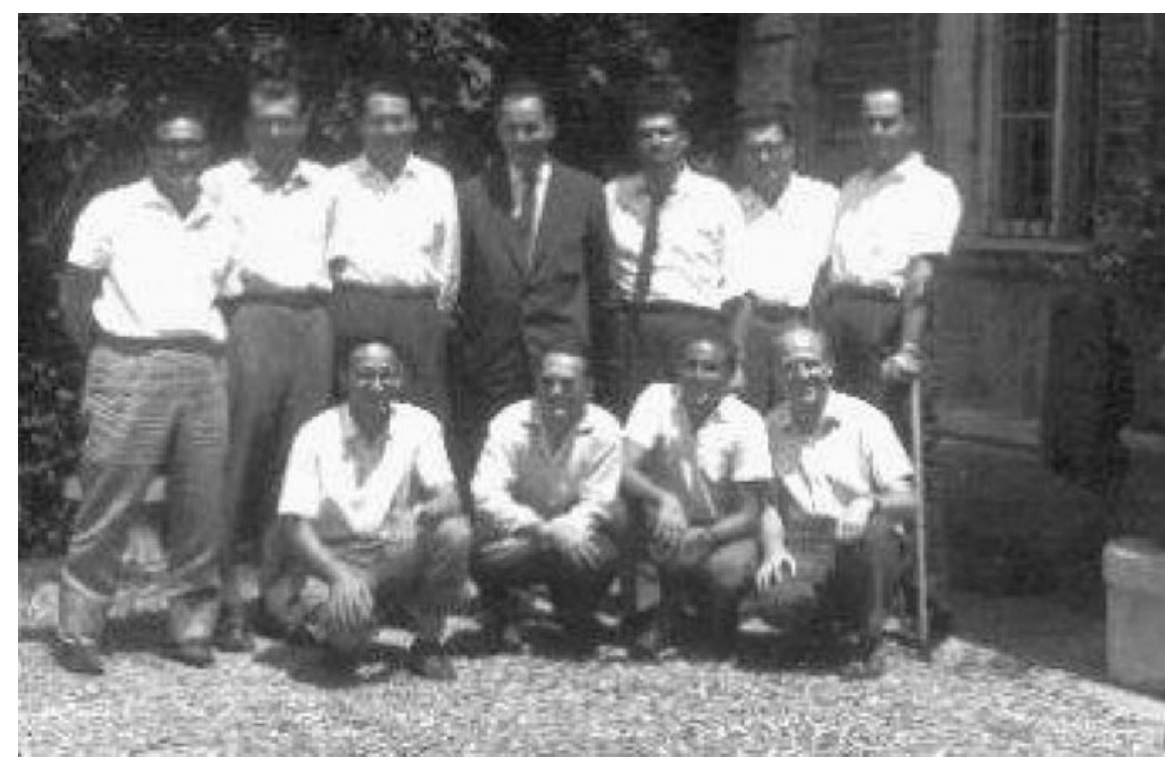

Figure 3 A photograph taken at Barbaricina. We can see the staff of the Olivetti Electronic Research Laboratory (not all the members are present). Mario Tchou is the third on the left in the second row.

Mario Tchou assigned a different task to every member of the staff. In 1957 at Olivetti Laboratory, five different groups were at work for developing respectively a) the machine instructions, b) the government system for magnetic tapes, c) the central government unit, d) the mainframe memory, e) the arithmetic unit. In the Laboratory, besides the main electronic activities for Elea 9003, there were also minor works in electronic devices for Olivetti mechanical calculators. One example is a device necessary for using punched tapes, called $c b s$, built by Pier Giorgio Perotto who next developed also Programma 101.

The supervisor of the Laboratory activities was Roberto Olivetti, while the head of the company, Adriano, visited Barbaricina only from time to time. 


\subsection{From Scientific Research to Industrial Development}

The manufacturing of the Elea computer developed into three main steps. In 1957, the first prototype was finished. It was mainly built with vacuum tubes and only the register for magnetic tapes was transistorized. This computer - known as Macchina zero (zero machine) and then called Elea 9001 - was not competitive in Mario Tchou's opinion. In fact, in those years the most important companies involved in computer manufacturing were developing transistorized mainframes. So, with the aid of his collaborators, Tchou restarted the project for a fully transistorized architecture and in 1958 the prototype of the business machine (Elea 9003) was almost finished. Between Elea 9001 and Elea 9003 another Elea machine (Elea 9002) - with standard vacuum tubes - was built.

In August 1958 Olivetti laboratory moved from Pisa to Borgolombardo, near Milan, where began the manufacturing of the transistorized computer. The laboratory building in Borgolombardo was on two-floor. On the ground floor the Elea central unit and the memory were produced - the I/O devices were built in Ivrea - while on the first floor there was the Elea 9003 computer at work. The prototype mainframe often required repairs and the servicing staff was set next to it.

Employees at Borgolombardo increased from some decades to some hundreds and then more than a thousand taking into consideration both the research staff and the manufacturing workers. Hierarchies substituted the flexible organization experienced in Barbaricina. Mario Tchou, now, was the head of the research activities but in Borgolombardo research and development had to coexist with the commercial goals.

In 1963, there was another move to Pregnana Milanese, in a strategic area along the Turin-Milan highway. The change of location happened after the official set up in 1962 of the Olivetti Electronic Department, which should coordinate all the factory activities in electronics.

Nevertheless, Olivetti electronic enterprise did not last. In 1960, Adriano Olivetti abruptly died and in 1961, Mario Tchou was also killed in a car accident. Two years later, in 1963, Olivetti suffered financial problems and the management decided to reduce loss selling to General Electric the Electronic Department, which required many investments. Due to unfortunate events and structural fragilities, the Olivetti engagement in computer science stopped in about a decade and the company went out of the mainframe market.

Although in 1965, the Italian company tried a new adventure in computer science with a desktop computer, Programma 101, which gained great business results. It was a forerunner of personal computer and its project had already started in the company Electronic Department. 


\subsection{The Architecture of Elea Computer}

The Olivetti Laboratory developed the central unit of Elea 9003 by an original project, although I/O devices (tape punch and reader, cardpunch and reader, printer and teletypewriter) were commercial products built by Olivetti and Olivetti-Bull. The main components of the computer were the memory, the logical-arithmetic unit, the central government unit, the tape government unit, and the on-line unit synchronizer.

The mainframe had a clock time of $10 \mu \mathrm{s}, 8$ characters instructions (2 characters for function/command, 4 characters for the address, 2 characters for the length), variable word size, magnetic cores for the main memory and magnetic tapes $^{3}$ as secondary memory devices. It could perform about 5,000 additions per second and the capacity of the main memory was extensible from 20,000 words to 160.000. It was built with germanium diodes and transistors and its power consumption was $4.5 \mathrm{~kW}$.

The most original features of the Olivetti mainframe were multiprogramming, the capability of handling an interruption, and optimize computer work (De Marco et al. 1999).

Multiprogramming was based on a completely automatic priority system that depended on the availability of hardware resources and requests. The maximum "multiprogramming level" available on Elea 9003 [...] was three. [...] The main architectural components that made multiprogramming feasible were the Internal and External Transfer Channels. [...] With this architecture Elea 9003 was able to multiprogram operations on tapes, operations on online I/O Units $[\ldots]$ and logical-arithmetic operations.

\subsection{The Problems of Technological Transfer}

In the development of Elea 9003, technological transfer from research to industrial manufacturing highlighted some structural problem of the Italian system. The financial effort needed by electronics was very heavy for Olivetti, which was still a 'multinational shop', mainly governed by members of only one family. Moreover, the Elea computers were not sold to customers, but rented to them, as in IBM practice. In that way, initial investments were recovered in a longer time. Financial resources were also necessary for the development of new Elea machines as the smaller Elea 6001 devoted to scientific research.

The software development required also new efforts because Elea business mainframes could not be programmed easily. The Olivetti software team, born in the last days in Barbaricina, experienced all the difficulties of computer programming at its very beginning.

\footnotetext{
${ }^{3}$ The Elea 9003 brochure also referred to magnetic drums as secondary memory devices, but they were never added to the mainframe (Bonfanti 2007).
} 
Mauro Pacelli, the mathematician who led the team, created PAlgol, a personal dialect of Algol, but an effective solution to software problems required the cooperation between Olivetti and its customers. For example, the Elea 9003 sold to Marzotto needed a long training period before it was fully operative.

The Italian situation was also peculiar because the national government did not help Olivetti in any way: it did not commission any computer - instead the national Treasury received free an Elea mainframe by Olivetti - nor it helped the company during the financial crisis occurred in 1963. When the Olivetti Electronic Department was sold to General Electric, the Italian government did not recognize as a national value the development of a home industry for computer research and manufacturing.

Mario Tchou, the leader of Olivetti Laboratory, had been aware of this criticality and he had already stated it in 1959 during an interview (published by the Italian newspaper Paese Sera) (Rao 2003)

Nowadays we have gained the same qualitative development of our competitors, but they receive consistent financial aids by their national governments. Electronic research, mainly for military applications, is generously funded by the US. Also Great Britain invests millions of pounds in the field. Olivetti effort is great, but other companies could hope in a better future than us because they receive public funding. ${ }^{4}$

\section{The International Framework of Computer Science}

\subsection{A Survey in Computer Science at the Beginning of the 1960s}

During the age of transition between vacuum tubes mainframes and transistorized computers, engineers and public officers interested in the field wrote detailed reports about the worldwide development of computer science. Throughout the Fifties new technologies of information processing were growing in United States, Europe and Japan. At the beginning of the Sixties in the United States there were «over ten times the number of medium and large-scale data processing equipment installations [...] than in the rest of the world» (Auerbach 1961).

The US leadership was due to earlier start in the field and was maintained by the Government support in research and development. The main computer manufacturers - such as IBM, RCA, Remington Rand, Sperry, DEC - invested in new solid state technologies and exported their mainframes in many foreign countries. In 1958 Sperry Rand started the development of a full solid state mainframe and in the same year IBM announced the 7070 all transistorized computer series, which was put on the market in 1960. In 1960, too, DEC commercialized the Programmed Data Processor (PDP 1) computer, full

${ }^{4}$ Paese Sera (November 18, 1959). The translation is mine. 
transistorized and very compact. In addition, in Europe and Japan the Fifties were a profitable age for development of information systems and at the beginning of the next decade digital computers were working throughout the area. In large part of Europe, computers were manufactured and seven countries were involved also in the commercial market. «[...] Great Britain clearly comes first (after the U.S.). She is followed by (West) Germany, the U.S.S.R., France and Japan» (Blachman 1961).

\subsection{The Situation in Great Britain, France, and Germany}

In Cambridge, Great Britain, was realized in June 1949 the Edsac, the first storedprogram electronic digital computer. In Manchester, both University and Ferranti Ltd. did relevant efforts in scientific and industrial computer development. In particular, Ferranti manufactured Atlas, a fully transistorized computer capable of operating on several programs simultaneously. Besides Ferranti, there were seven more computer manufacturers in Great Britain and they delivered about two hundreds computers in about a decade.

In the Western European continent, Germany and France had a leading role in computer science. Germany was involved in computer science and making since the late Thirties, when Konrad Zuse realized the first relay computer. A decade after the II World War in the Western side of the country there were national computers manufacturers (as Zuse, Siemens, Telefunken, Standard Elektrik) and two factories of foreign builders as IBM and Remington Rand. Telefunken, in particular, was making the most advanced machine, Telefunken TR 4, fully transistorized. Many German universities were also involved in computer development and scientific training.

In France Compagnies des Machines Bull, Société d'Electronique et d'Automatisme and Société Nouvelle d'Electronique were the national computer developers. In particular, Bull was the most important punched-card machine manufacturer all over Europe, North Africa, and South America and since 1950, it had a business agreement with Olivetti for the sale of punched-card systems in the Italian market. Bull Gamma 60 mainframes had multi-threading capabilities through asyncronism of processing units and input/output channels. They were realized by a combination of germanium transistors, magnetic core memory and still a few vacuum tubes.

\subsection{Computers in USSR and Japan}

Moving toward the East, in USSR the development of computer science was mainly due to the Ukrainian engineer Sergey A. Lebedev. At Lebedev's Institute in Moscow there were laboratories working on transistors, core materials, thin magnetic films, and magnetic circuits. 
In the Far East, instead, Fujitsu produced the first Japanese computers during the Fifties. In 1954 the company built Facom 100 with relay technology but in less than a decade it moved from old technologies (vacuum tubes and parametron, a kind of oscillating circuit with the same functions of transistors) to solid-state electronics. In 1956, Fuji Photo Film Company built with vacuum tubes the Fujic, the first Japanese computer with a memorized program, and between 1956 and 1957 a transistorized computer were built at the Electrotecnic Laboratory of Japan. The Japanese universities of Tokio, Keio and Osaka were also involved in computer science research.

\section{Solid-state Electronics in Italy}

\subsection{The First Root of ST Microelectronics}

In 1956, the Nobel Prize for Physics was awarded to William Shockley, John Bardeen, and Walter Brattain «for their researches on semiconductors and their discovery of the transistor effect» done ten years before at Bell Laboratories in US. Also in the field of solid-state devices, the US strongly kept a leading role. In Europe the main producers were Siemens and Philips. Solid-state components were not manufactured in Italy, another obstacle for the development of transistors computers.

Olivetti in joint venture with Telettra, an Italian telecommunication company that shared the same problem, founded in 1957 the SGS (Società Generale Semiconduttori). In fact, Roberto Olivetti, the manager of Olivetti electronic assets, and Mario Tchou, the head of the Olivetti Laboratory, thought that a computer factory should take part in the basic industry of electronic devices.

From 1960 also the US company Fairchild was involved in the society, which next developed into the multinational STMicroelectronics. At the beginning of the Sixties in the SGS laboratories near Milan worked also another key-figure of computer science, Federico Faggin who developed there a method of manufacturing MOS (Metal Oxide Semiconductors) integrated circuits and designed also the first two commercial ones.

\subsection{International Cooperation}

The first Italian staff in Olivetti Electronic Research Laboratory knew only a little about computers and physicists, engineers and technicians strengthened their competences by self-training and international experiences. This requirement was precisely stated in the company job advertisement appeared in 1955 on the main Italian newspapers for recruiting the laboratory staff. 
Franco Filippazzi, who developed the Elea 9003 main memory, for example, visited more than once Philips Laboratories in Eindhoven, where he could see the most advanced European solid-state devices. Besides the drain of international knowledge, Olivetti management tried also to promote a grid of European electronic manufacturers.

There were meetings with the British company ICT (International Computers and Tabulators), the French company Bull, the German Siemens, but the effort was unsuccessful. European manufacturers could not find an agreement about common technological standard and scientific knowledge sharing.

\section{Advertising and Science Communication}

\subsection{Olivetti Advertising Office}

At the middle of the twentieth century, 'Olivetti style' was a recognized feature of the Italian company all over the world. In 1952 the Metropolitan Museum of Modern Art in New York exhibited some of the more successful Olivetti products as the mechanical calculator Divisumma 14 and the typewriter Lettera 22.

The elegant design was a main component of the Olivetti brand and since 1931, the company founded an Advertising Office, whose consultants were architects, painters, writers and poets. The duties of the office were the design planning and the promotion of advertising campaigns. The office staff worked in strong collaboration with both the management and the project engineers.

Electronics, as a new and promising company assets, should be respectful of Olivetti style, so in 1958 Adriano Olivetti entrusted the architect Ettore Sottsass of the mainframe design. Elea 9003 cabinets created by Sottsass were about a meter high, far less than the big ones generally used for mainframes. The result was an open space where technicians and engineers could see all the system with only a look.

Moreover, every cabinet was connected to others by aerial conducts (shown in Figure 4) and so it was unnecessary to build a new pavement under which store cables and ventilation pipes. Elea cabinets could also be separated from one another (they had a "wing" structure) for easier transport and installation of the computer. Ettore Sottsass also designed the Elea console, very functional and user-friendly before this expression was born (an overview of the mainframe is in Figure 5). 


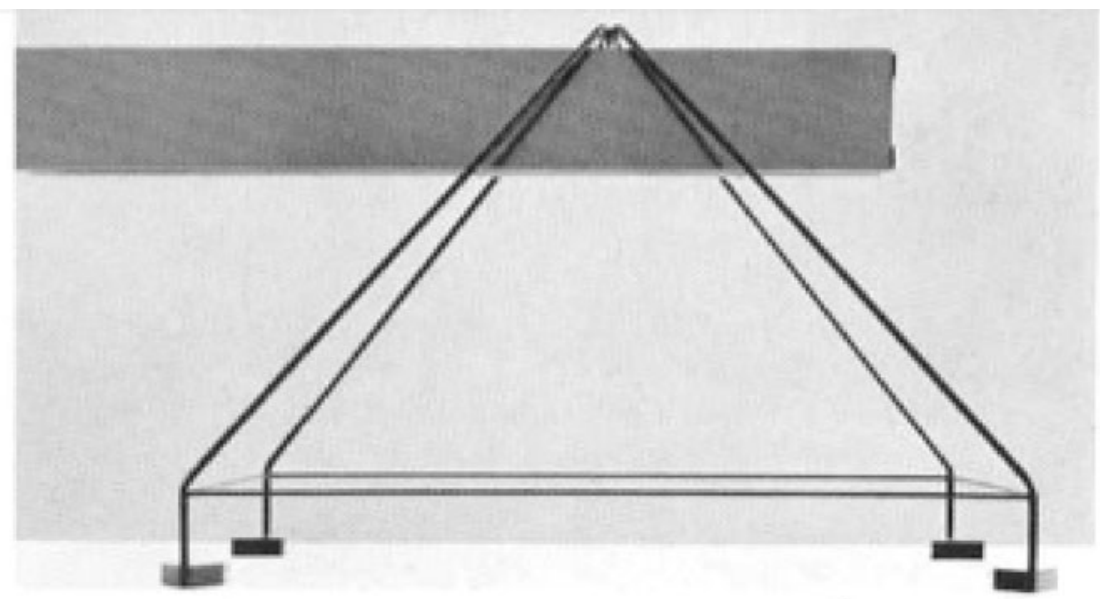

Figure 4 The aerial conducts between Elea 9003 cabinets. By courtesy of Associazione Archivio Storico Olivetti, Ivrea (Italy).

The aesthetic of Elea 9003 was strongly influenced by the sovereign Olivetti philosophy, in which machines should fulfil the greatest usefulness for people. This feature was highlighted also in the advertising campaign for Olivetti mainframe and the commercial name Elea is again a smart communication trick. On one side Elea is the abbreviation of the Italian words for Electronic Automatic Computer, but on the other it recalls the town of Elea where flourished in the Antiquity a famous philosophical school. It is claimed that the commercial name Elea was chosen by Franco Fortini, a famous Italian writer and translator who worked for Olivetti Advertising Office in those years.

\subsection{The Future is Now}

In 1959 and 1960, when Elea was officially announced, Olivetti promoted the new electronics activities with brochures, advertising, on the press and in broadcasting.

In October 1959 a popular Italian magazine of the time, Epoca, published a 'servizio industriale' (an article realized by the Advertising Office) about the Olivetti mainframe and the Electronic Research Laboratory. The article is a masterpiece of photojournalism. The first part of the article summarizes Olivetti approach to electronics as a key way for industrial development and shows photographs taken at Olivetti headquarters in Ivrea and in the Research Factory at Borgolombardo, where Elea 9003 was working. 


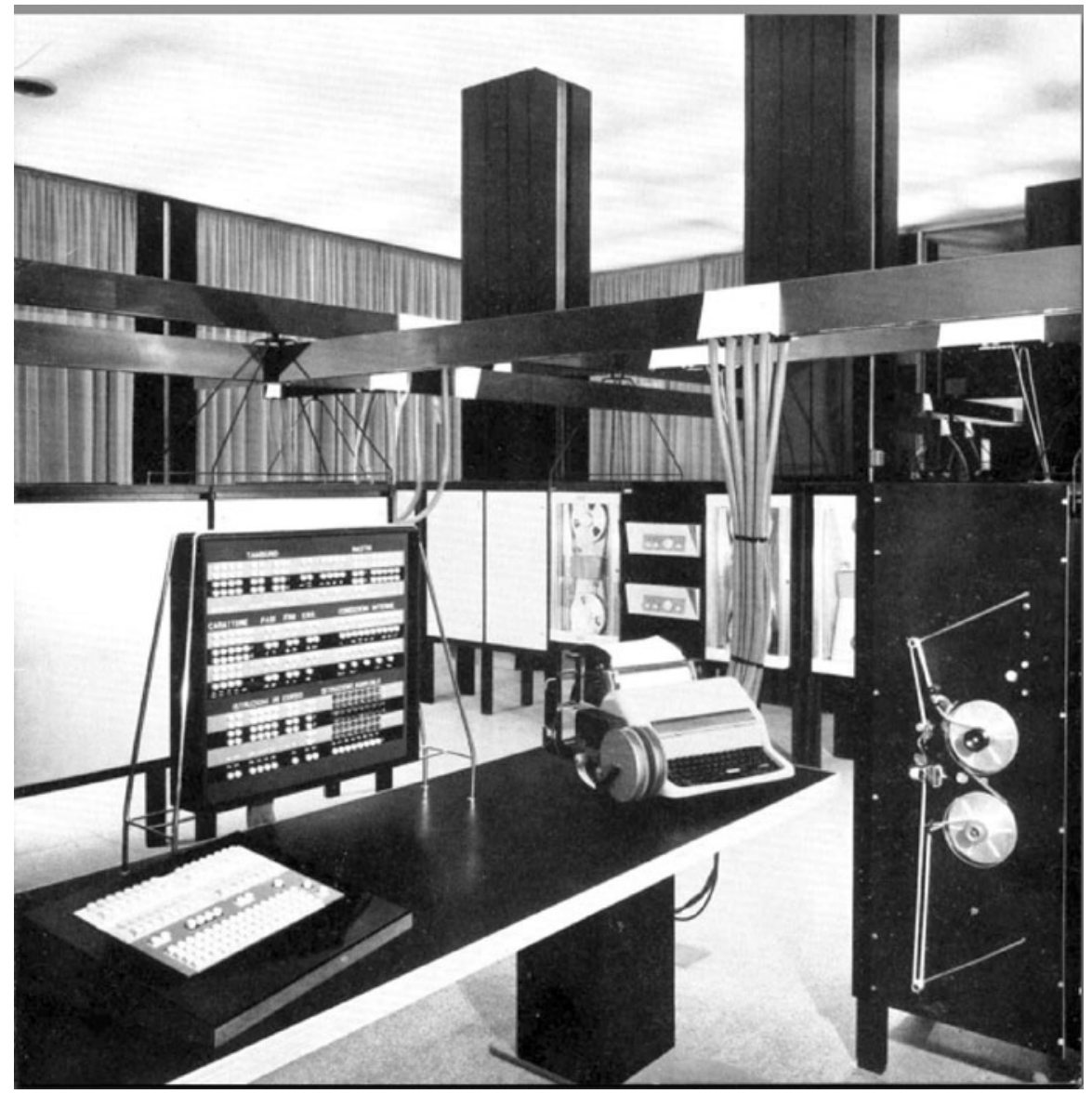

Figure 5 Olivetti Elea 9003. In the foreground the console of the mainframe. By courtesy of Associazione Archivio Storico Olivetti, Ivrea (Italy).

The written text remarks the switching of lights in the console of the mainframe and the high potential of the computer («more than 100,000 characters could be written and are available for reading every minute»). In the second part of the article, a photographic gallery displays the main features of Elea 9003. Ten images with a legend explain the information process from data entry to output results, giving some remarks about the function of the main memory and the role of government units.

Elea 9003 and the Research Laboratory in Borgolombardo are also shown in the documentary Elea classe 9000 produced in 1960 by Olivetti Film Office. In about half an hour there is a summary of calculating machines history and a perspective look of the Elea development and functions. Graphic animations, 
beautiful photography, and the original soundtrack make the film a masterpiece. The documentary explains both the research goals - there is also the head of the laboratory, Mario Tchou, who describes the work done by his team - and the business value of the machine. Graphic animations show how Elea is helpful in the management of car industry and a voice over suggests also that the mainframe could be useful in financial business, archives administration, registry office and much more.

Basic mainframe features and functions are explained to the documentary audience by metaphors, smart graphic solutions, and analogies. In fact at the beginning of the Sixties computer science was quite unknown in Italy and its popularization should be developed from nothing. Olivetti approached the challenge with a mix of advertising techniques (first of all, brand reliability) and science communication attitudes, explaining the great potential of Elea machine.

In 1960 also the annual diary ${ }^{5}$ created by Olivetti was devoted to the evolution of writing machines from mechanical typewriters to the Elea mainframe, which was described as 'the electronic thinking machine'. The Italian painter Bruno Caruso, who realized the drawings for the diary, represented Elea mainframe thanks to the metaphor of the electronic brain. Logic circuits and the memory of the computer are related to human anatomy. Caruso plays with the identity of functions and at the same time, he underlines the substantial differences between the levers and the mechanisms in traditional typewriters and the greater potentialities of the Elea computer.

\section{Conclusion}

The development of the Italian mainframe Elea 9003 is an interesting case of industrial research because the architecture of the mainframe, which was original and competitive in the national market, started from scratch by a drain of international experiences and on-the-job training of the scientific staff.

Although, the challenge of technological transfer could not be properly overcome due to several factors: Olivetti experienced financial fragilities and there were inner contrasts in the management after the unexpected deaths of Adriano Olivetti and Mario Tchou. Moreover, the national market was very limited and the Italian government did not help in any way the company. Between scientific research and computer business there was - and in Italy often there is again - a tangled bond, which could choke even a promising project.

${ }^{5}$ It was a prestigious gift for customers created by Olivetti during the Sixties and devoted, year after year, to different topics. The 1960 diary was entitled Dalla calligrafia alla memoria (i.e. From calligraphy to memory). 


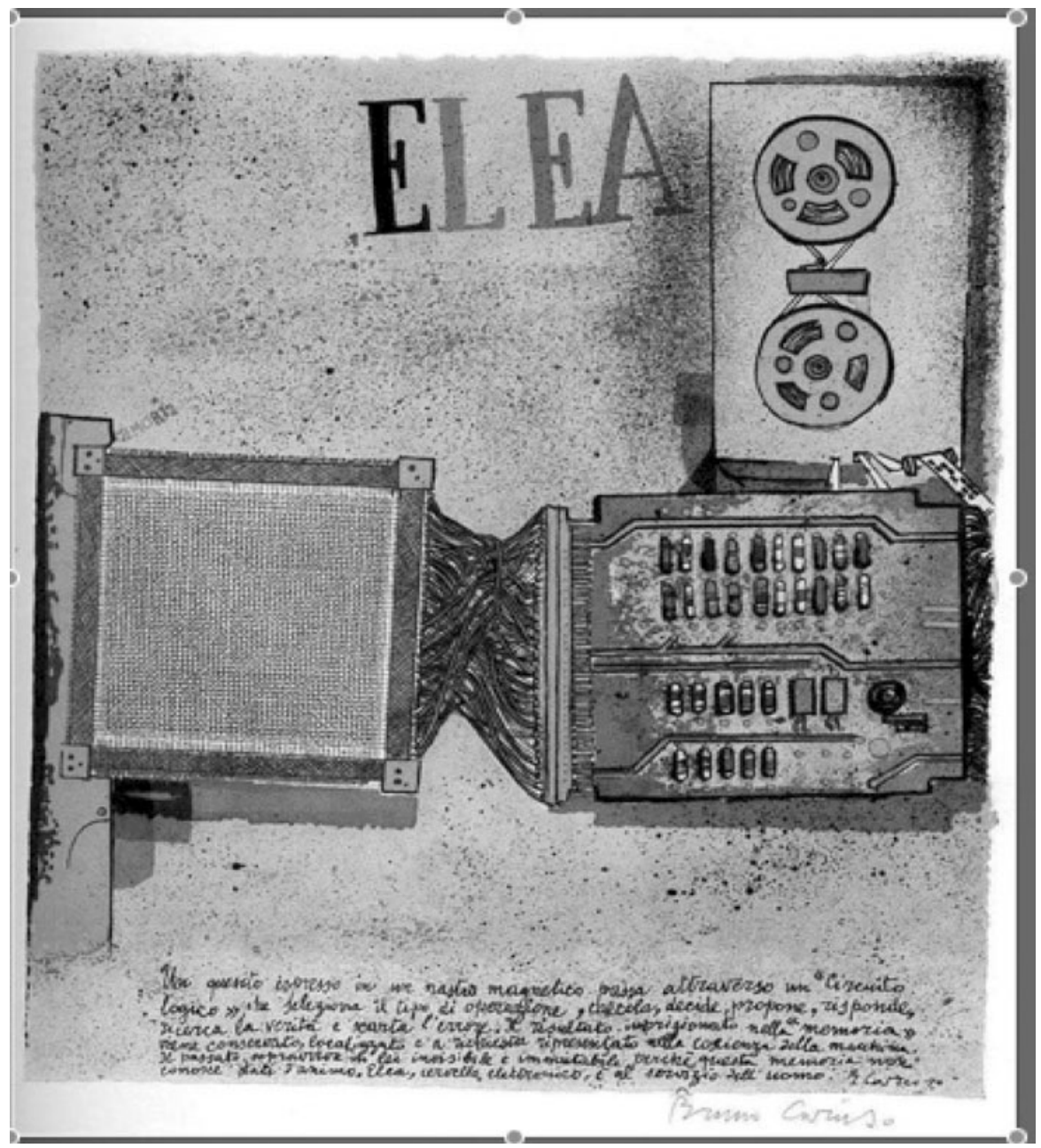

Figure 6 A drawing of the Elea 9003 computer done by Bruno Caruso and published in Olivetti journal during 1960. The caption is a poetic description of how Elea 9003 works. "A question impressed on a magnetic tape pass through a logic circuit which decides the operation, perform it, decides, proposes, answers, searches for the truth and rejects the error. The result is imprisoned in the memory where it is stored, localized and, under request, proposed another time in the consciousness of the machine. The past survives in the machine, invisible and unchanging, because this memory has no mood. Elea, electronic brain, is at work for mankind". By courtesy of Associazione Archivio Storico Olivetti, Ivrea (Italy).

However, the manufacturing of Elea 9003 was one of the first computer science initiatives in Italy and, though not at all successful, it spread many seeds. 
The first root of Programma 101, the scientific training of Italian computer experts and a few attempts in science communications are all outcomes of the activity done in a decade by Olivetti Research Laboratory.

Acknowledgments: I would like to thank all who have supported me in collecting information about Mario Tchou's international experience and Olivetti Electronic Research Laboratory. I am grateful to Jocelyn K. Wilk of the Columbia University Archives and to Giuseppe Rao who has done an extensive research about Mario Tchou and Olivetti Laboratory. Thanks to Franco Filippazzi for our conversation in Milan and to Corrado Bonfanti for documents and suggestions.

\section{References}

1. Auerbach IL (1961) The international impact of computers. Commun. ACM 4,10: 466

2. Blachman NM (1961) The state of digital computer technology in Europe. Commun. ACM 4,6:256-265

3. Bonfanti C (2007) L'industria del computer in Italia. In: L'informatica - Lo sviluppo economico, tecnologico e scientifico in Italia, Edifir, Firenze (in Italian)

4. De Marco G, Mainetto G et al (1999) The Early Computers of Italy. IEEE Ann. Hist. Comput. 21, 4:28-36

5. Filippazzi F (2005) Elea: storia di una sfida industriale. PRISTEM 12-13:43-57 (in Italian)

6. Filippazzi F. and Sacerdoti G. (1992) Progetto Elea: il primo computer made in Italy. Atti del Convegno Internazionale sulla Storia e Preistoria del Calcolo Automatico e dell'Informatica (Siena, September 10-12, 1991), $3^{\text {rd }}$ edn, AICA, Milano (in Italian)

7. Gallino L (2003) «Un neo da estirpare»: l'informatica. In: La scomparsa dell'Italia industriale, Einaudi, Torino (in Italian)

8. Morelli M (2001) Dalle calcolatrici ai computer degli anni Cinquanta. FrancoAngeli, Milano (in Italian)

9. Rao G (2003) La sfida al futuro di Adriano e Roberto Olivetti. MEFRIM 115,2:643-678 (in Italian)

10. Rao G (2005) Mario Tchou e l'Olivetti Elea 9003. PRISTEM 12-13:85-119 (in Italian)

11. Soria L (1979) Informatica: un'occasione perduta. Einaudi, Torino (in Italian)

12. Ware W.H. et al (1960) Soviet Computer Technology - 1959. Commun. ACM 3,3:131-166 


\section{Appendix A}

\section{Columbia EAninersity \\ in the Citpof Ifrw}

\section{NOMINATION FOR APPOINTMENT}

[Fill out and send to the President a sufficient number of copies for submission

to each of the Faculties concerned in the appointment]

To the President of the University:

Date June 3, 1954

Name of candidate in full VARTO TCHOU

For the position of Assoctete in Mectricnl Ingineerlng

To succeed $74 \operatorname{sel} 19$

Appointment to date from July 1,1954, To expire June 30,1955

At an annual salary of $\$ 4500$

Academic degrees (Include institution and date) B.E.E., Catholic University of Anerics, 19/7; H.S., Polvtochnic Institute of Broolayn, 1249.

Address 2/37 Yehb Atranie, Brem 68, Nern York

To be presented to the Faculty ordcradtias of Bngineering

REMARXS

II nomination is for new appointment, state whether candidate beld School of General Studies or Summer Session appointment during previous year; if nomination is for reappointment, give list of scholarly activities involving publication and research during previous year.]

Old Budget Line Ho. 17
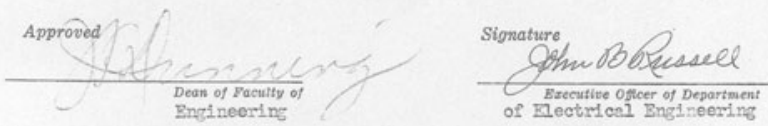

Dean of Paculty of

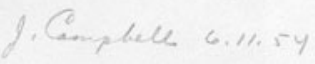

Dean of Focutity of

Figure 1 Mario Tchou's Nomination for Appointment from July 1954 to June 1955 at Columbia University. By courtesy of Columbia University Archives. 


\section{Appendix B}

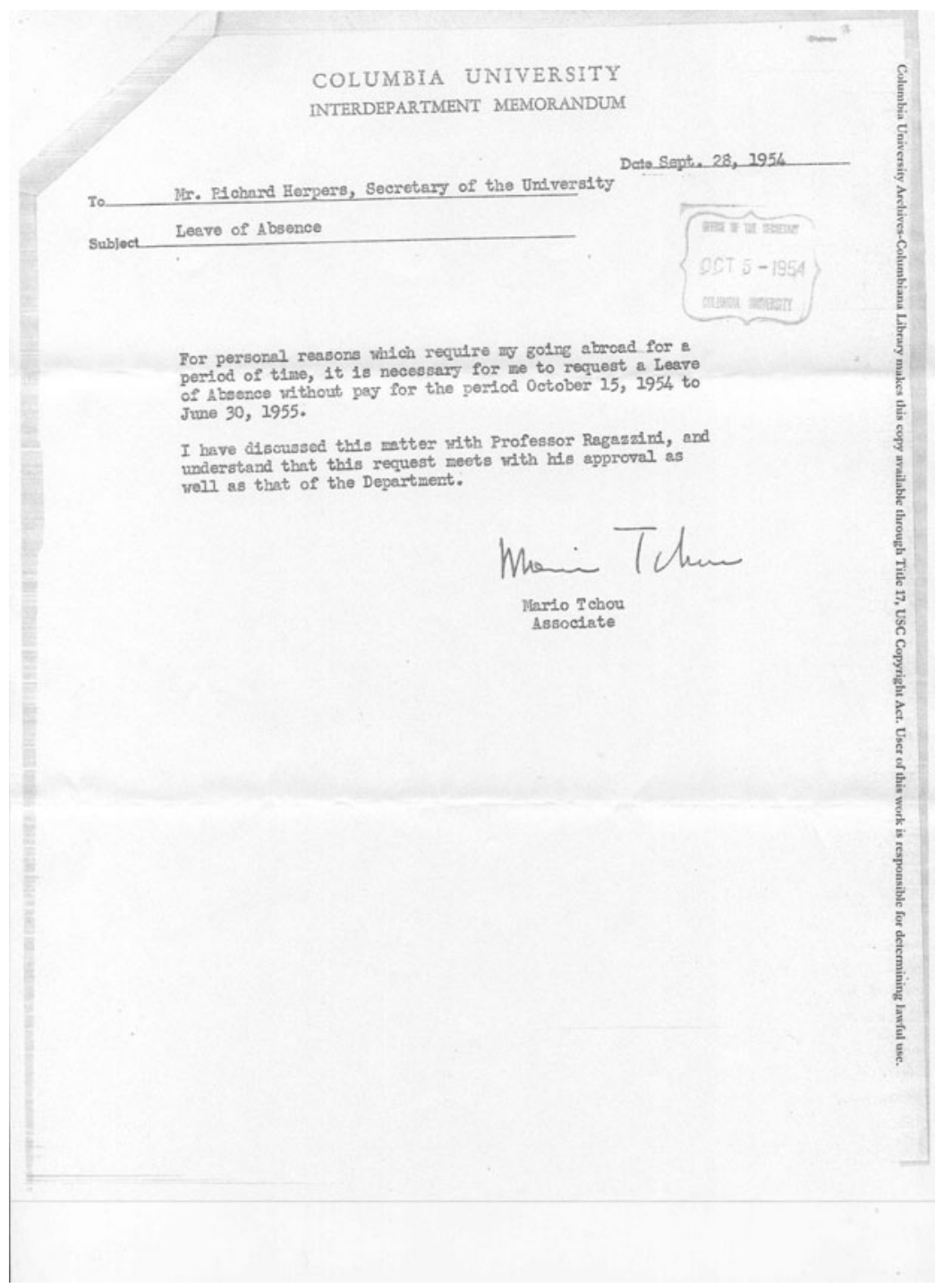

Figure 2 Memorandum for Mario Tchou's Leave of Absence (Sept. 28, 1954). By courtesy of Columbia University Archives. 